\title{
WORLD
}

RESOURCES

WORKING PAPER

\author{
I N S T I T UT E
}

\section{TOWARD A TRADABLE, LOW-CARBON PRODUCT STANDARD FOR STEEL POLICY DESIGN CONSIDERATIONS FOR THE UNITED STATES}

\section{EXECUTIVE SUMMARY}

\section{Highlights}

- A low-carbon product standard for steel in the United States that establishes an emissions intensity benchmark with tradable credits can drive a reduction in emissions intensity in the steel industry. The standard would provide incentives to adopt existing abatement options and to invest in emerging technologies.

- A low-carbon product standard for steel should maximize coverage of emissions related to steel production while minimizing administrative complexity.

Addressing the barriers to abatement in the steel industry will require a suite of complementary policies. A low-carbon product standard can play a significant role, but additional policies will be needed to fully decarbonize the sector.

This paper offers recommendations on key design considerations for a low-carbon product standard for steel, including what products and emissions should be covered by the standard, how to define an emissions intensity metric and set a benchmark, reporting requirements, crediting and compliance, and how to address the risk of leakage and competitiveness concerns. Due to a lack of publicly available data, this paper does not recommend specific levels for policy design elements.

\section{CONTENTS}

Executive Summary .................................

1. Introduction ........................................ 3

2. The U.S. Steel Industry......................... 4

3. Decarbonizing the Steel Industry.................. 7

4. Designing a Low-Carbon Product

Standard for Steel .................................. 9

5. Other Considerations .............................. 13

6. Conclusions and Recommendations.............. 15

Abbreviations ..................................... 15

Endnotes....................................... 16

References .......................................... 16

Acknowledgments................................ 18

About the Authors ................................. 18

About WRI ..................................... 18

Working Papers contain preliminary research, analysis, findings, and recommendations. They are circulated to stimulate timely discussion and critical feedback, and to influence ongoing debate on emerging issues.

Suggested Citation: Feldmann J., and K. Kennedy. 2021. "Toward a Tradable, Low-Carbon Product Standard for Steel: Policy Design Considerations for the United States.” Working Paper. Washington, DC: World Resources Institute. Available online at doi.org/10.46830/wriwp.20.00113. 


\section{Decarbonizing the Steel Industry}

The United States must significantly decarbonize every aspect of its economy, including the industrial sector. Innovative policies will be required to provide strong incentives and to drive U.S. manufacturers to adopt technologies and practices that will lead to a reduction in industrial greenhouse gas (GHG) emissions. In recent decades, the United States has significantly shifted its production of steel from processes with high emissions intensities to ones with lower emissions intensities that predominantly use recycled steel as an input. However, steelmaking still accounts for over 80 percent of direct emissions due to metals manufacturing (EPA 2021), 5 percent of industrial emissions, and approximately 1.5 percent of total GHG emissions in the United States (EPA 2020b). Furthermore, steel production is estimated to account for 8 percent of global emissions, so it is important for global leaders in steel production, such as the United States, to take the lead in reducing steel emissions.

\section{Commercially available technologies and new} technologies offer opportunities to substantially reduce or even eliminate emissions in the steel industry. The use of green hydrogen; renewable energy; and carbon capture, use, and storage could offer nearterm and long-term decarbonization opportunities. Furthermore, new electrolytic steelmaking processes, similar to those used in manufacturing other metals, have the potential to drastically alter low-emissions steelmaking.

A variety of policy tools will be needed to bring these technologies to market. These include policies such as government procurement requirements, a carbon tax, cap-and-trade programs, production tax credits, carbon storage tax credits, renewable energy standards, funding for research and development, and voluntary certification programs. Each of these policies performs optimally when applied to a certain phase of technology development. For instance, research and development funding programs are clearly most effective in the early phases of technology development. Renewable energy standards, production tax credits, and certification programs provide incentives for technologies in the diffusion phase of development. Finally, carbon pricing policies, such as a carbon tax or a cap-and-trade program, provide incentives for widespread, commercially available technologies.
While other policy mechanisms are well established and their potential impacts on decarbonization are well understood, low-carbon product standards have received less attention from policymakers. A low-carbon product standard is a sector-specific, market-based regulation that establishes an emissions intensity standard for a set of defined products. Companies that manufacture products covered by the standard either generate tradable credits or obligations based on the degree to which their emissions intensity is lower or higher, respectively, than the benchmark.

\section{Design Considerations for a Low-Carbon Product Standard for Steel}

A low-carbon product standard applied to the U.S. steel industry would advantage low-emissions steelmaking technologies and result in a shift toward these technologies and away from highemissions technologies. The design details of a low-carbon product standard for steel must be tailored specifically to the products and emissions profile of the steelmaking process. Crucially, a low-carbon product standard for a trade-intensive industry, such as the steel industry, must contain certain design elements that deter the relocation of production to unregulated markets.

\section{Design recommendations for a low-carbon stan- dard for steel in the United States:}

Product choice should include intermediate steel products in the form of sheets, plates, bars, beams, pipes, and tubes. These product categories correspond to the first sale of steel products from steel mills to consumers of steel mill products, which defines the point of regulation.

- Product benchmarks initially should be set to a fraction of the industry-wide average emissions intensity (tons of carbon dioxide equivalent emissions divided by tons of product produced) or to the average emissions intensity of top performers. The benchmarks should be reduced over time in regular and predetermined intervals according to an assessment of abatement opportunities and in line with emissions reduction goals.

Reporting should be at the company level and include facility-level data regarding GHG emissions, material inputs, material outputs, electricity 
consumption, electricity generation, and fuel use by fuel type for each covered product manufactured in a facility that produces more than a certain amount of steel per year or releases more than a certain amount of carbon dioxide equivalent emissions per year. This facility-level data can be used to determine the emissions intensities of covered products.

Emissions included in the product standard benchmark should be all Scope 1 (direct; generated on-site) and Scope 2 (indirect; due to purchased electricity) emissions as well as significant Scope 3 (indirect; offsite; upstream) emissions associated with the manufacturing of the product.

Tradable credits should be generated by companies that have an emissions intensity lower than the benchmark, whereas companies with an emissions intensity higher than the benchmark should be required to surrender credits.

Leakage and competitiveness concerns should be addressed by applying the low-carbon product standard to all steel products produced and sold in the United States. Importers of upstream products (such as coke, iron ore, steel slabs, and sheets) and downstream steel products (final products that contain steel, such as cars and appliances) must comply with the standard as well, subject to a cutoff threshold linked to the value of steel in the product relative to the total value of the product.

\section{About This Working Paper}

This working paper is designed to offer insight regarding the role of a low-carbon product standard in providing targeted incentives for decarbonizing the steel industry in the United States. The paper provides an overview of the steel industry and options for reducing its emissions, and it reviews key design elements of a low-carbon product standard and includes preliminary recommendations. Additional work is needed to better understand the emissions and economic implications of a low-carbon product standard for steel and to determine how a low-carbon product standard compares to, and might complement, other policies aimed at decarbonizing steel manufacturing and other industrial sectors.

\section{A companion working paper considers the same issues for the cement industry.}

\section{INTRODUCTION}

Greenhouse gas (GHG) emissions due to industrial processes have received relatively little attention from policymakers and the public. This is due in part to the complexity of the industrial supply chain and its exposure to international trade. This trade intensity raises concerns that regulations that increase production costs will affect the competitiveness of domestic producers relative to unregulated foreign producers. Furthermore, the complexity of the supply chain and production processes makes measuring and attributing emissions difficult. These difficulties and concerns have resulted in the creation of policies that incentivize emissions abatement in the easy-to-abate sectors. Although this increases economic efficiency in the short term, it results in the delay of technological advancements and emissions reductions in the hard-to-abate sectors.

Though competitiveness concerns need to be addressed (e.g., by applying the product standard to imports), there is still a need for policies that can drive reductions in hardto-abate industrial emissions while limiting the loss of production to foreign producers. Recently, clean product standards - referred to as low-carbon product standards in this paper-have been proposed as a way to address both competitiveness issues and the delay of emissions reductions in hard-to-abate sectors, such as industry (King et al. 2020). A low-carbon product standard is a performance standard that takes a sectoral approach to decarbonization by focusing on a product or a set of products in a specific sector (see Box 1).

This working paper lays out design elements and recommendations for a low-carbon product standard for the U.S. steel industry and considers the potential effects of such a standard. The paper also explores alternative policy designs, acknowledging that the topic requires further study to determine which policy design is best suited for the U.S. steel industry.

The research presented in this working paper is based on literature review and consultation with industry stakeholders, policymakers, and academic researchers. Industry information, data, and abatement options have been gathered from, and are based on, government sources, industry trade organizations, and academic research. Existing policies, policy design considerations, and low-carbon product standard policy design elements were gathered from, and are based on, regulatory documents, industry trade literature, and academic literature. All data and data analysis are based on publicly available data. 


\section{Box 2 | What Is the Role of a Low-Carbon Product Standard?}

As used in this paper, a low-carbon product standard is

a sector-specific regulation that provides incentives to

reduce the carbon intensity of manufactured products. This

technology-neutral policy establishes an emissions intensity,

or benchmark, for a set of defined products. Companies that

make or import products covered by the standard generate

credits if their emissions intensity is lower than the benchmark

or obligations if their emissions intensity is higher than the

benchmark. The number of credits or obligations companies

generate depends on the amount that a company's emissions

intensity is above or below the benchmark. Because

companies that generate credits can sell them to those

that need to purchase them, the policy provides a financial

incentive for companies to reduce the emissions intensity of

their production process.

As the benchmark is lowered over time, the product standard can help drive innovation by increasing the need to reduce

emissions intensity. In addition, clear signals about the

expected trajectory of the benchmark-how much it will be

lowered and over what time frame-can provide long-term

incentives for investment in innovation.

Driving deeper changes in the steel industry will require activating multiple policy levers. Because current abatement costs in other sectors are lower than abatement costs in steelmaking, cross-sectoral carbon prices have had limited effect to date in decarbonizing the steel industry. Sector-specific pricing programs can provide more targeted incentives to decarbonize sectors that might not respond to an economy-wide price. California's Low-Carbon Fuel Standard demonstrates this approach, and a similar approach can be used for manufactured products through a clean

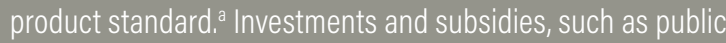
investment in carbon dioxide transport or tax credits for carbon capture, use, and storage, can also reduce the costs of abatement significantly and lead to more investment in the technologies necessary to realize the deep decarbonization of steel and other industrial sectors. The specific design elements of a low-carbon product standard for steel are discussed in more detail in Section 4.

Source: a. King et al. 2020.

\section{THE U.S. STEEL INDUSTRY}

The industrial sector accounts for approximately 29 percent of all GHG emissions in the United States (including indirect emissions due to electricity use), and the steel industry is responsible for approximately 5 percent of total U.S. industrial emissions (EPA 2020b). To achieve deep decarbonization in the United States, it is essential that all industries, including the steel industry, embrace process improvements, industry best practices, and new and innovative technologies. In the steel sector, a shift toward low-emissions manufacturing could include using alternative fuels for heating processes; carbon capture, use, and storage (CCUS); and new iron ore reduction technologies.

Steel is ubiquitous in today's society and is used in buildings, automobiles, appliances, and many other products. Steel is made through the reduction (removal of oxygen and other elements) of iron ore, which occurs naturally in the earth's crust in the form of hematite $\left(\mathrm{Fe}_{2} \mathrm{O}_{3}\right)$, magnetite $\left(\mathrm{Fe}_{3} \mathrm{O}_{4}\right)$, goethite $(\mathrm{FeO}(\mathrm{OH}))$, limonite $\left(\mathrm{FeO}(\mathrm{OH}) \cdot n \mathrm{H}_{2} \mathrm{O}\right)$, and siderite $\left(\mathrm{FeCO}_{3}\right)$. Iron ore reduction involves the stripping of oxygen from iron ore by the burning of either a carbon-rich material, such as coke (obtained by heating coal in the absence of oxygen), or a hydrogen-rich material, such as natural gas or hydrogen gas, in the presence of iron ore. The result of this process is nearly pure elemental iron, which can then be combined with varying amounts of carbon and alloying elements (such as nickel, chromium, manganese, or zinc) in order to create a wide array of steel products with a variety of physical and chemical properties.

Nearly all steel currently produced in the United States is made in either an integrated mill or a minimill. An integrated mill transforms iron ore into steel using a blast furnace to reduce the iron ore and a basic oxygen furnace to adjust the carbon and alloy content of the steel. A minimill primarily melts recycled steel using an electric arc furnace (EAF) to produce new steel products. In 2017 there were 9 integrated mills and 112 minimills in the United States, with integrated mills accounting for around one-third of domestic steel production and minimills accounting for around two-thirds.

Another aspect of modern steelmaking that is growing in significance is the direct reduction of iron ore-so-called because the process uses coal, natural gas, or hydrogen to reduce iron ore instead of using coke. The direct reduction of iron ore currently occurs in dedicated facilities, and its products - direct-reduced iron and hot- and cold-briquetted iron, 
which are compressed direct-reduced iron products - are used in both integrated mills and minimills. In 2020 there was one direct-reduced iron facility and two hot-briquetted iron facilities in the United States (USGS n.d.).

In an integrated mill, steel is generally produced by loading processed lump iron ore, coke, and limestone into a blast furnace where the ore is reduced and the impurities are removed. Sinter and pellets, which are agglomerated iron ore fines and other minerals, can also be added to the blast furnace, and oil and pulverized coal can be added as fuel and reduction agents. The hot metal produced by the blast furnace, called pig iron, is approximately 96 percent elemental iron, 4 percent carbon, and trace levels of other elements. This hot metal is loaded into a basic oxygen furnace along with lime, alloying metals, scrap iron and steel, and direct-reduced iron. These materials are heated to around $1,800^{\circ} \mathrm{C}$, and excess carbon is removed by blasting oxygen into the furnace.

As the name suggests, a minimill is much smaller in size compared to an integrated mill, lacking both a coke furnace and a blast furnace. In a minimill, an EAF uses an electric current to melt recycled steel scrap, pig iron, and direct-reduced iron to produce new steel products.

The direct reduction of iron ore is characterized by reduction without melting or the use of coke; it is usually performed using either coal or natural gas. Direct-reduced iron can be used in blast furnaces and in EAFs in the production of high-quality steel products. Production can be flexible regarding fuel, with facilities using natural gas as a reduction agent able to switch to coal or hydrogen and vice versa.

Steel exits the steelmaking furnace (basic oxygen furnace or EAF) in the form of liquid hot metal, which is immediately formed into semifinished products: slabs, billets, blooms, or ingots. These products are then reheated and further processed at the steel mill into so-called finished products: slab is formed into flat products, such as sheets and plates; billets are formed into mostly long products, such as reinforcing bars, pipe, tubing, and wire; blooms are shaped into I beams and other heavy structural products; and ingots are typically shipped to other facilities to be used in forming slabs, billets, or blooms.

Finished products are sold and shipped to construction, automotive, machinery, energy, appliance, and defense companies, where they are made or incorporated into the final consumer-facing products. The construction industry accounted for 44 percent of U.S. fabricated steel consumption in 2019, and the automobile industry accounted for 28 percent. Machinery and equipment (9 percent), energy (6 percent), appliances (5 percent), and other uses (8 percent) accounted for the remaining consumption (USGS 2020).

Figure 1 depicts the key materials and processes involved in steelmaking and their approximate emissions intensities. It is important to note that emissions intensities can vary from facility to facility as a result of a variation in raw materials and fuels used, facility and equipment age, facility design, technologies used, production capacity, products manufactured, management practices, and other factors.

\subsection{Production, Consumption, and Trade}

In 2019, global production of steel was 1,870 million metric tons (Mt). In the same year, the United States had a steel production capacity of $111 \mathrm{Mt}$ and manufactured 88 Mt (AISI 2019) - fourth globally behind China, India, and Japan.

In 2018, the top three steel companies in the United States accounted for 73 percent of production, and the top six accounted for 94 percent of domestic steel production (ITA 2020). In 2019, apparent U.S. steel use (domestic production minus exports plus imports) was $97.7 \mathrm{Mt}$, and true steel use (apparent use plus net indirect imports, which is defined as the trade of finished products that contain steel) amounted to 127.1 Mt (USGS 2020; worldsteel 2020).

Although the U.S. steel industry mainly exports finished steel products to Canada and Mexico, imports of finished products are more evenly distributed, with South Korea, Japan, Brazil, and Russia contributing significantly to U.S. imports. In 2019, the United States imported $27 \mathrm{Mt}$ of intermediate steel products and exported 6.7 Mt (USGS 2020), which amounted to the largest direct steel trade deficit and one of the largest direct steel trade volumes in the world (worldsteel 2020). The United States also has the largest indirect steel trade deficit, which amounted to net imports of 27.3 Mt in 2018 (worldsteel 2020). This trade intensity of steel in the United States has historically made it difficult to impose regulations on the industry, and it is also why a policy designed to reduce GHG emissions in the industry, such as a low-carbon product standard, must be applied not only to all steel produced in the United States but to imported steel products as well. 


\section{INTEGRATED MILL}

Coal

Fine ore

\section{Raw material preparation}

Ironmaking

Steelmaking

\section{Rolling and finishing}

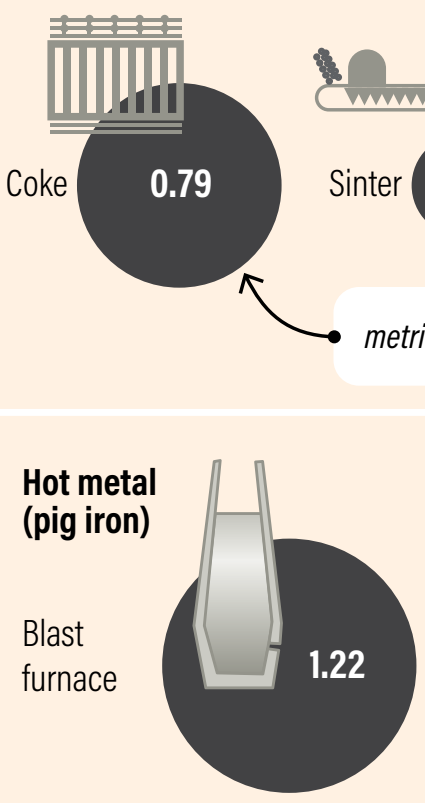

Steel billet, bloom, and slab

Basic oxygen furnace

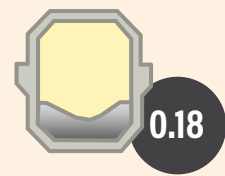

Steel plates

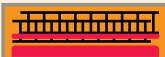

Reheating
Rolling
Treating
Coating
Finishing

\section{DRI}

Fine ore

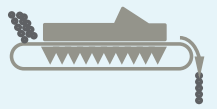

Pellet

\section{MINIMILL}

\section{Recycled steel}

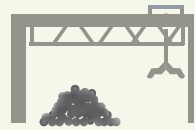

Steel scrap $\bullet \mathbf{0 . 0 0 5}$

metric tons of carbon dioxide equivalent per metric ton of steel produced

\section{Direct-reduced iron}

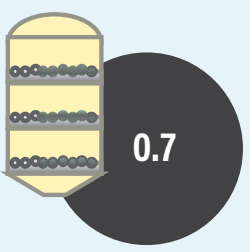

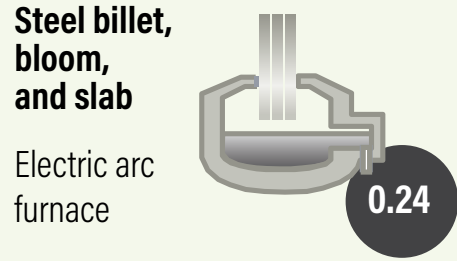

Steel bars, pipes, wires, tubes, etc.

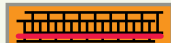

0.1
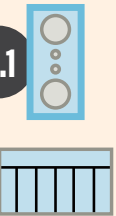

Reheating
Rolling
Structural mill

0.1

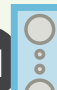

Notes: DRI = direct-reduced iron. The typical emissions intensities for some products and processes are shown in units of metric tons of carbon dioxide equivalent per metric ton of steel produced. Lime and alloying elements are not shown.

Sources: Adapted from worldsteel 2019; data from EPA 2009 and Pardo et al. 2012. 


\section{DECARBONIZING THE STEEL INDUSTRY}

The integrated mill steelmaking process emits an average of approximately 2.5 metric tons $(\mathrm{t})$ of carbon dioxide equivalent $\left(\mathrm{CO}_{2} \mathrm{e}\right)$ for every metric ton of steel produced. These emissions are primarily due to process emissions, which result from the interaction of oxygen in the iron ore with carbon monoxide produced by the combustion of coke, and the combustion of fuels and use of electricity for process heating. Minimill steel production from 100 percent scrap emits approximately $0.4 \mathrm{tCO}_{2}$ e per metric ton of steel, which is an 80 percent reduction in emissions relative to an integrated mill (Conejo et al. 2020). If 100 percent direct-reduced iron is used, then emissions due to steel production in an EAF total about $1.1 \mathrm{tCO}_{2}$ e per metric ton of steel produced if natural gas is used in reduction and about 1.5 $\mathrm{tCO}_{2} \mathrm{e}$ per metric ton of steel produced if coal is used in reduction (Conejo et al. 2020). It is also important to note that the emissions intensity of a minimill is highly dependent on the emissions intensity of the electricity used to power the EAF.

In 2019, direct emissions in the U.S. steel industry amounted to $73 \mathrm{MtCO}_{2} \mathrm{e}$, or 1.1 percent of total U.S. emissions (EPA 2020b, 2021). Approximately $42 \mathrm{MtCO}_{2} \mathrm{e}$ direct (Scope 1) emissions were due to industrial process and product use (IPPU), and $31 \mathrm{MtCO}_{2}$ e were non-process direct (Scope 1) emissions due to on-site fuel combustion (EPA 2020b, 2021). In 2019, the steel industry purchased 212 million British thermal units (MMBtu), or 62,100 kilowatt-hours (kWh), of electricity (EIA 2020), resulting in approximately $27.6 \mathrm{MtCO}_{2} \mathrm{e}$ of indirect emissions due to purchased electricity, assuming a national average emissions intensity of 0.99 pounds $\mathrm{CO}_{2} \mathrm{e} / \mathrm{kWh}$ (EIA 2020; EPA 2020b, 2021). In 2018, 99.98 percent of U.S. steel IPPU emissions were in the form of $\mathrm{CO}_{2}, 0.02$ percent were due to methane emissions, and trace amounts were due to nitrous oxide (EPA 2020b).

U.S. steel industry IPPU emissions fell 59 percent from 1990 to 2018 - from $104.7 \mathrm{MtCO}_{2}$ e to $42.6 \mathrm{MtCO}_{2}$ e (EPA 2020b) - with production levels remaining approximately the same (89 Mt were produced in 1990 and $87 \mathrm{Mt}$ in 2018). This reduction in emissions was mainly due to a restructuring of domestic steel production toward minimills and their dependence on steel scrap for production. In 2019, energy consumption in the iron and steel industries comprised 654 trillion Btu (49.5 percent) from coal, 432 trillion Btu (32.7 percent) from natural gas, 212 trillion Btu (15.9 percent) from purchased electricity, 19 trillion Btu (1.4 percent) from petroleum products, and
6.25 trillion Btu (0.43 percent) from propane and other fuels (EIA 2020). The iron and steel industry accounted for 1.54 percent of total U.S. electricity consumption in 2019.

\subsection{Low-Emissions Steelmaking}

Energy and material efficiency have long been a focus of the steel industry, and low-emissions steelmaking has been the subject of intense research since the mid-1990s (Birat et al. 1993; Worrell et al. 1999). Energy efficiency measures and innovative, low-emissions technologies offer a wide range of emissions abatement opportunities for the U.S. steelmaking industry (IEA 2020).

Opportunities to reduce energy consumption in the iron and steel industry by using state-of-the-art technology amount to approximately 240 trillion Btu per year, and research and development (R\&D) opportunities could further reduce energy use by 150 trillion Btu per year (DOE 2015). These opportunities include reductions of 37.2 kilograms $(\mathrm{kg})$ of $\mathrm{CO}_{2}$ e per metric ton of steel for blast furnace processes, $8.85 \mathrm{kgCO}_{2}$ e for EAF steelmaking, and $45.9 \mathrm{kgCO}_{2} \mathrm{e}$ for direct-reduced iron production (DOE 2015; EPA 2020a). ${ }^{1}$ Even greater emissions reductions could be possible if processes were optimized to reduce emissions intensity rather than energy efficiency.

Several innovative technologies that have either been demonstrated at the facility or laboratory level, or that are still in the research phase of development, have the potential to revolutionize the steel industry and drastically reduce or even eliminate GHG emissions in the steelmaking process. These technologies can be divided into three main categories based on their use of hydrogen, carbon, and electricity.

Using hydrogen to reduce iron ore nearly eliminates direct carbon emissions from the ironmaking process. Indirect emissions due to hydrogen production can be addressed by the use of green hydrogen produced by renewable energy sources such as solar and wind, blue hydrogen produced from natural gas combined with carbon capture, or emerald hydrogen produced from biomass waste combined with carbon capture. Many initiatives and pilot programs are aimed at developing hydrogenbased steelmaking technologies. For example, Hydrogen Breakthrough Ironmaking Technology (HYBRIT) is a pilot project that began in 2016 in Sweden - headed by steelmaker SSAB, iron ore mining company LuossavaaraKiirunavaara Aktiebolag (LKAB), and gas provider 
Vattenfall- that aims to demonstrate nearly zero-carbon, fossil-free steelmaking using hydrogen (SSAB n.d.).

Carbon-based strategies for reducing emissions from steelmaking include increased efficiency, fuel switching, and CCUS. Fuel switching opportunities exist in using coal, natural gas, or charcoal to displace coke use in blast furnaces, which would reduce upstream emissions associated with making coke. Furthermore, coke ovens, blast furnaces, basic oxygen furnaces, combustion units, and direct reduction furnaces offer carbon capture opportunities. For example, carbon capture technology is currently being used in a steel plant in the United Arab Emirates, where captured $\mathrm{CO}_{2}$ is then transported via pipeline to be used for enhanced oil recovery (Global CCS Institute n.d.).

By using electricity to reduce iron ore, electrolytic technologies have the potential to eliminate direct GHG emissions in the steel industry. However, as with hydrogen-based technologies, decarbonizing the power sector will be important for limiting indirect emissions for these technologies. Boston Metal, a U.S. research firm, is spearheading R\&D of molten-oxide electrolysis steelmaking technology and has demonstrated success at the laboratory scale. The process uses electrodes and a liquid oxide electrolyte at a temperature of $2,000^{\circ} \mathrm{C}$ to reduce iron ore. In Europe, the Siderwin project-a consortium of 12 companies headed by ArcelorMittal and funded by the European Union's Horizon 2020 program - aims to build a pilot electrolysis plant by 2022 (ArcelorMittal 2019).

\subsection{Policy Barriers and Solutions}

U.S. steelmaking facilities face a variety of operational barriers to adopting low-carbon steelmaking, including the cost, the availability of low-carbon fuels, the lack of infrastructure and markets for CCUS options, technological hurdles, and the production downtime for retrofits. Meanwhile, barriers to policy implementation include trade exposure, a complex supply chain, and a lack of publicly available data regarding production processes and production levels. In addition to a low-carbon product standard, there are a number of policy solutions that are available to address these barriers, including a carbon tax; cap-and-trade programs; tax credits for CCUS; renewable energy standards; and funding for R\&D, government procurement requirements, and certification programs. A renewable energy standard could drive emissions reductions in EAF production because a large portion of EAF emissions are due to purchased electricity. Similarly, a renewable fuel standard could incentivize, for instance, the use of charcoal derived from waste biomass in the blast furnace.

Funding for R\&D spurs innovation and reduces barriers to entry. Current funding for R\&D in the steel industry is provided through the U.S. Department of Energy's Advanced Manufacturing Initiative, though funding levels have not been sufficient to spur substantial innovation in the sector (Balserak 2020). In addition to R\&D funding, further incentives for technology deployment and adoption will be needed to drive change in the industry. The Buy Clean California program - a government procurement program - establishes global warming potential limits for products purchased by state agencies (California State Legislature 2017). Government procurement programs offer opportunities for federal and state governments to influence the emissions intensity of steelmaking by offering markets for low-carbon products.

Voluntary programs, such as the Energy Star program administered by the U.S. Environmental Protection Agency (EPA), can result in increases in efficiency as well as adoption of low-carbon technologies. In the Energy Star program, the EPA collects facility-level data from integrated steel mills to inform an energy performance score based on the mill's electricity consumption and production, fuel use by fuel type, and intermediate and final products manufactured (Boyd et al. 2016). The EPA then issues a certification level to each reporting facility based on its energy performance relative to industry best practices. Such a program helps facility managers identify energy- and cost-saving opportunities while providing recognition for low-carbon production.

Emissions trading programs, such as the European Union's emissions trading scheme (EU ETS), provide incentives for emissions reductions through the direct pricing of carbon emissions. The EU ETS includes R\&D funding as well. The EU ETS currently allocates free allowances to the steel industry based on emissions benchmarks due to the industry's high level of trade exposure, though the free allocation will reduce over time. The European Union is also considering implementing a carbon border adjustment as early as 2023 (Allianz Research 2020). 
4. DESIGNING A LOW-CARBON PRODUCT STANDARD FOR STEEL

A product standard is a targeted policy tool that is intended to drive a reduction in emissions in a specific industry or due to a specific product. The key elements of a low-carbon product standard are:

Product choice and point of regulation

An emissions intensity benchmark, which declines over time, for each product category

The generation of tradable credits for companies whose emissions intensity is lower than the benchmark

The generation of obligations for companies whose emissions intensity is higher than the benchmark

\section{Coverage of imported products}

There are many design options for each of these elements, and choices made regarding one element can drastically affect the viability of options for another element. We have approached these design questions from the perspective of implementing the standard through stand-alone legislation, which offers the greatest flexibility in design. It may be possible to implement a low-carbon product standard under existing legal authority, though such an approach would affect the design options available. The key elements and recommended policy designs for a lowcarbon product standard for the U.S. steel industry are discussed in detail below.

\subsection{Product Choice and Point of Regulation}

Recommendation: The products covered by a lowcarbon product standard for steel in the United States should be finished products, including sheets, plates, bars, beams, pipes, and tubes. The sale of these products by the steel mill to companies that produce final steel products should be defined as the point of regulation.

Due to the complexity of the steel industry supply chain, which includes the import and export of many raw, intermediate, and final products at the national level and at the facility level, a low-carbon product standard for steel should seek to balance programmatic efficiency with emissions reduction goals. The three points of regulation in the U.S. steel industry that can potentially achieve this goal are the intermediate products made in the ironmaking processes, steelmaking processes, and finishing and rolling processes, as shown in Figure 1. At these points in the manufacturing process, the products are well-defined and relatively few in number.

Of these potential product categories, finished products are best suited for use as product categories for a low-carbon product standard for steel. This is due to the fact that these products are the first point of sale for steel, which is the optimal point of regulation for a low-carbon product standard (King et al. 2020). This point of regulation would require steel mills to comply with reporting protocols under the standard.

Existing policies generally divide steel product categories into the industry's two main production routes-blast furnace/basic oxygen furnace and EAF-and define roughly 5-10 product categories comprising raw materials, iron products, and finished products. The EU ETS defines five product categories - three related to integrated mill production (coke, sinter, and hot metal) and two related to minimill production (EAF carbon steel and EAF alloy steel). Canada's Output-Based Pricing System (OBPS) defines similar steel product categories, with two categories related to production of steel primarily from scrap iron and steel (minimill and EAF) and four categories related to the production of steel from iron ore (integrated mill and blast furnace/basic oxygen furnace). The OBPS also defines two product categories for pellet production (Government of Canada 2020). 
These existing policy approaches achieve the goal of balancing implementation complexity with emissions coverage. The production of coke, sinter, and hot metal (via blast furnace) accounts for approximately $2.2 \mathrm{tCO}_{2}$ emissions per metric ton of steel produced, or around 90 percent of emissions in an integrated mill. Furthermore, a vast majority of EAF production is currently dedicated to carbon steel and alloy steel.

This approach allows for the fact that the integrated route has traditionally created higher-quality, new steel products from virgin iron ore, such as automotive sheet, whereas the minimill has traditionally created lower-quality steel products from recycled steel, such as rebar and structural beams. This distinction, however, has increasingly blurred in recent years, as minimills venture further into the production of higher-quality steel products and as both production routes increase the use of alternative iron units, such as direct-reduced iron.

With this increasing overlap in material usage and products, establishing separate product categories for these two production routes is not recommended. Furthermore, as new production technologies become commercially available, it is important to design lowcarbon policies that are as technology neutral as possible to take advantage of innovation and market forces that can help drive emissions reductions.

Meanwhile, the benefits of defining product categories only for finished products include a simplification of reporting protocols, a small number of products, a technology-neutral design, and a consistent and well-defined point of regulation, which is defined as the point of sale of finished products to consumer-facing product manufacturers. This approach does require the inclusion of Scope 2 and Scope 3 emissions, however, and this entails the reporting of new data that have not been collected under previous regulations, such as the EPA's Greenhouse Gas Reporting Program. This new data will, however, come closer to accounting for the total GHG emissions due to the steelmaking process, which will allow for a closer comparison with other products that are often substituted for steel, such as aluminum, concrete, and cross-laminated timber. Emissions covered under the recommended design for the product standard are discussed in detail below (see Section 4.2).

One of the challenges of defining product categories that are upstream from consumer-facing products is that it presents leakage and competitiveness concerns related to the importation of foreign products. To prevent this, products that are downstream from the point of regulation must also be subject to the standard if their steel content constitutes a significant share of their value (King et al. 2020). The details of applying a product standard to imported products is treated in Section 4.6.

\subsection{Emissions Covered}

Recommendation: A low-carbon product standard for steel should include Scope 1 (on-site; direct), Scope 2 (off-site; due to purchased electricity), and significant Scope 3 (off-site; upstream) emissions of all GHGs emitted due to the manufacturing of a covered product. Scope 3 emissions should include emissions associated with coke, lime, and direct-reduced iron production, but it should not include emissions associated with the manufacturing of alloying elements or other upstream or downstream emissions. For the purposes of a single product standard for steel, it is sufficient to include only the major sources of emissions that have the potential to differ between steel production technologies; this maintains a technologyneutral approach. It is not recommended to include emissions credits for recycling steel at its end of life because this would add significant administrative complexity, and these emissions reductions are accounted for in the use of recycled steel in minimills.

A low-carbon product standard should be designed to cover direct and indirect GHG emissions that result from product manufacturing. These emissions can be defined using scope terminology as laid out in the Greenhouse Gas Protocol. ${ }^{2}$ Scope 1 emissions are due to on-site processes, whereas Scope 2 emissions include emissions due to electricity usage. Scope 3 emissions are defined as upstream emissions - for example, due to off-site feedstock materials production, fuel production, or transportation - or emissions due to downstream product or by-product use or disposal. Both upstream and downstream emissions can be important aspects of life cycle emissions for steel products.

Scope 2 emissions play an important role in a lowcarbon product standard for steel because emissions from to minimill production are highly dependent on the emissions intensity of the purchased electricity used by the EAF. If Scope 2 emissions are not included, then a separate set of product categories should be defined for the integrated production route and the minimill production route. However, the exclusion of 
Scope 2 emissions would make it impossible to compare the emissions intensities of products from these two production routes.

Likewise, some Scope 3 emissions greatly affect the emissions intensity of steel in both the integrated production route and the minimill production route. In the integrated mill production route, important Scope 3 emissions include those related to the production of lime and coke, which amount to over $800 \mathrm{kgCO}_{2}$ per metric ton of steel produced. In the direct-reduced iron/minimill route, the production of direct-reduced iron results in the emission of approximately $700 \mathrm{kgCO}_{2}$ per metric ton of steel produced (see Figure 1). Excluding either of these emissions sources from a low-carbon product standard would drastically affect the emissions intensity of a steel product and reduce the potential for emissions reductions in the industry. Therefore, it is recommended to include Scope 3 emissions in the standard due to lime, coke, and directreduced iron production.

The production of alloying and coating elements is also a substantial source of Scope 3 emissions for certain types of steel, including stainless steel (often alloyed with chromium, nickel, and other alloys). However, it is not recommended to include the Scope 3 emissions associated with alloying elements in the standard because this would substantially increase the complexity of reporting and product category design. It should be noted, however, that in order to compare alloyed steel with substitutable products, these Scope 3 emissions should be considered.

\subsection{Emissions Intensity Benchmark}

\section{Recommendation: An emissions intensity benchmark should initially be set to a percentage of the industry- wide average emissions intensity for each product category, in units of $\mathrm{tCO}_{2}$ e per metric ton of product. The benchmark should be reduced over time in regular and predetermined intervals according to an assessment of abatement opportunities and subject to emissions reduction goals.}

When setting a product benchmark for a low-carbon product standard, it is important to first define the scope of emissions covered under the standard. The industry-wide average emissions intensity of a product is then determined by dividing total covered emissions (in $\mathrm{tCO}_{2} \mathrm{e}$ ) by the total mass of product produced (in metric tons). The benchmark should then be set at some percentage of this average emissions intensity. For example, the California cap-and-trade program sets the benchmark at 90 percent of this average. An alternative approach, used in the EU ETS, is to set the benchmark at the average of the top 10 percent of producers.

To drive the necessary reduction in emissions, the benchmark should decrease over time. This reduction schedule should be predetermined according to abatement opportunities in the industry and emissions reduction goals. A predetermined benchmark reduction schedule would provide the industry with clear credit price signals and would identify and incentivize specific emissions reduction goals for the sector. However, this schedule should be updated every few years to reflect changes in the industry and other conditions.

\subsection{Reporting}

Recommendation: The reporting of emissions should be required from producers and importers of a covered product. A threshold of around 25,000 t of product per year, or 25,000 $\mathrm{tCO}_{2}$ e emissions per year, would limit administrative complexity and ensure coverage of a majority of emissions. Imports of covered products should be assigned a default emissions intensity in the absence of specific emissions intensity data.

A first step in implementing a product standard is to establish specific and detailed reporting protocols. Existing protocols include facility-based emissions monitoring and reporting as well as product-based reporting such as environmental product declarations (EPDs). Reporting emissions at the facility level is a well-established method already in use in many emissions policies. Reporting through an EPD, though a well-established method, is not currently uniform in practice. Product category rules would first need to be carefully designed for each covered product under the low-carbon product standard for EPDs to be a feasible vehicle for reporting product emissions intensities. Given the efforts that would be required to implement reporting protocols using EPDs, and since it is recommended that product categories be defined in a way that aligns with the point of regulation (i.e., the sale of finished steel products), it is not recommended to use EPDs but rather to require reporting at the facility level.

Under this recommended approach, domestic producers of covered products would be required under the product standard to report total facility emissions (Scope 1 and Scope 2), all material inputs, and all material outputs 
(including the amount of each covered product manufactured). From the material inputs and outputs data, significant Scope 3 emissions could be estimated using nationwide averages of emissions due to these materials. Alternatively, the company could report verified Scope 3 emissions covered under the product standard. Importers could be assigned a default emissions intensity value by country of origin, which they could opt to override based on verified data.

This facility-based approach would have the advantage of building on existing data reporting protocols that exist through the EPA's Greenhouse Gas Reporting Program and its Energy Star program. However, this approach would necessitate the collection of more detailed data regarding emissions and manufacturing processes in integrated mill facilities and would require minimills and direct-reduction mills to begin reporting production, emissions, and process data.

\subsection{Crediting and Compliance}

The low-carbon product standard would apply to U.S. steel producers and importers. In the case of emissions exceeding the benchmark, these companies would have a compliance obligation to surrender credits equal to the quantity of emissions produced in excess of the amount allowed by the standard. Conversely, they would generate credits if their emissions were lower than the level allowed by the standard.

Steel producers would either generate or be required to surrender credits as follows:

$$
C=B * P-E
$$

where $C \equiv$ number of credits, $B \equiv$ benchmark $\left(\mathrm{tCO}_{2} \mathrm{e} /\right.$ metric ton of product), $P \equiv$ production (metric tons of product), and $E \equiv$ emissions $\left(\mathrm{tCO}_{2} \mathrm{e}\right)$.

When the number of credits is positive, credits are generated; when it is negative, credits must be surrendered. Steel importers would either generate or be required to surrender credits in a similar manner:

$$
C=B * I-E_{\text {intensity }} * I
$$

where $C \equiv$ number of credits, $B \equiv$ benchmark $\left(\mathrm{tCO}_{2} \mathrm{e} /\right.$ metric ton of product), $I \equiv$ imports (metric tons of prod$\mathrm{uct}), E_{\text {intensity }} \equiv$ emissions intensity $\left(\mathrm{tCO}_{2} \mathrm{e} / \mathrm{metric}\right.$ ton of product).

\subsection{Leakage and Competitiveness}

\section{Recommendation: A low-carbon product standard for steel should apply to all covered steel products sold in and imported to the United States. Imported upstream products and feedstocks, such as coke or pig iron, should be assigned a default emissions intensity in the absence of more detailed emissions intensity data regarding its specific production. Steel components contained in imported indirect steel products (such as automobiles or appliances) should be assessed for their emissions intensity and covered under the standard (see Reporting and Crediting and Compliance sections).}

A low-carbon product standard that is applied at the point of first sale for steel sold in the United States would ensure that unregulated foreign markets would not have a competitive advantage. A facility operating in an unregulated market wishing to sell steel products in the United States that are covered under the low-carbon product standard could have the option of reporting an emissions intensity for the product's embodied carbon. In the absence of these data, a default value for emissions intensity could be assigned to the product. This emissions intensity would need to be set at a value that ensures domestic producers would not be placed at a competitive disadvantage relative to foreign producers.

To minimize administrative complexity, the standard should incorporate a threshold for the value of steel contained in the imported product as a percentage of the product's total value. This threshold should be set at a level at which the competitiveness of domestic steel producers would not be affected. For instance, King et al. (2020) suggest setting a threshold of 5 percent of the value of steel relative to the total product value based on the industry total requirements table of the U.S. Bureau of Economic Analysis (BEA 2018). 


\section{OTHER CONSIDERATIONS}

Legal avenues. A low-carbon product standard could be implemented at the federal level either through new legislation or through the Clean Air Act. New legislation is the preferred route since it would provide an opportunity to comprehensively design a standard incorporating the best principles outlined in the sections above. If new legislation were passed, it would likely be broad based rather than steel specific; as such, it would require addressing issues related to intersectoral credit trading. In addition, if the political will exists to pass new legislation, including a low-carbon product standard, there would likely be other related procurement or R\&D policies that would need to be considered in the program timeline, benchmarks, and design. Incremental steps toward creating a low-carbon product standard, such as implementing a federal "buy clean" procurement policy, might be possible without new legislation.

The Clean Air Act (Section 111[b] and 111[d]) gives the EPA jurisdiction to regulate air pollution from new and existing steel facilities, respectively. There are pending legal questions surrounding its use for regulating GHG emissions, the ability to use tradable standards, and federal versus state jurisdiction in setting emissions thresholds. However, there is also reasonable expectation that the EPA's authority would withstand judicial review. ${ }^{3}$

Application of these provisions to implement a clean product standard would require developing output-based emissions intensity standards for steel facilities, which is an approach the EPA has previously taken for other sources, such as electricity generating units. Because Section 111 regulates facility emissions, this approach would mean limiting the emissions covered to direct emissions and not including those associated with purchased electricity or upstream production of lime and coke. Because these are significant emissions for steel production, this would limit the effectiveness of a low-carbon product standard developed using these provisions. The Clean Air Act would not apply to importers of foreign steel, and maintaining the competitiveness of U.S. industry could therefore require policies to address the competitiveness concerns of workers and industry, potentially including a border tax adjustment, incentives for domestic low-carbon production, or other modifications to help ensure a level playing field for domestic producers.
Cost containment. The analysis of current emissions intensities and abatement options conducted to establish a declining emissions intensity benchmark for a low-carbon product standard for steel would provide a basis for estimating the future supply of, and demand for, credits. However, a mismatch in supply and demand could result in very high or very low credit prices. Cost containment measures, such as a price ceiling and a price floor, could be included in the program design to limit this price uncertainty.

Price ceilings and floors set a maximum and minimum price, respectively, on the cost of a credit (or a ton of carbon). A price ceiling such as the one in place in California's LCFS can ease the concerns of industry by providing certainty via an upper cost limit. However, a price ceiling fails to incentivize abatement that costs more than the cap, which could reduce economic efficiency. A price ceiling could be set at the expected cost of backstop abatement technology such as direct air capture. Recent studies have suggested that the cost of direct air capture could fall to $\$ 150-\$ 200$ over the next decade (Baker et al. 2020; Keith et al. 2018). A price ceiling at that level would avoid forcing steel producers to invest in abatement that is more expensive than this backstop technology.

A price floor would further enhance price predictability, offering greater certainty in decisions to invest in emissions reductions. For example, a price floor can avoid very low allowance prices like those seen in the early phases of the EU ETS. Although an upper limit on credit prices might give regulators greater confidence in setting an ambitious trajectory for the declining benchmark, a price floor would send a clear signal of commitment to decarbonization, even if regulators set too low a benchmark.

Another option that would provide cost containment would be to broaden the suite of abatement options capable of generating credits for compliance under the program. This could be done by allowing credit trading with other programs (e.g., a tradable performance standard for cement) or by allowing the generation of credits for activities outside the steel facility, such as direct air capture.

Product substitution. Product substitution and product flexibility are important considerations in designing a low-carbon product standard. Although one of the benefits of a low-carbon product standard is that it spurs emissions reductions in a specific sector or for a specific product, alternative products that can be substituted for the 
covered product might see a relative drop in production costs, thus driving a change in relative market share. In the case of steel, substitutable products include aluminum, concrete, and cross-laminated timber. If the alternative product is emissions intensive, this could reduce or eliminate the emissions benefit of the standard. This effect can be prevented by establishing a low-carbon product standard for the substitutable product, offering incentives for purchasing the lower-emissions product, or offering subsidies.

Consumer impacts. The consumer impacts of a low-carbon product standard for steel are expected to be minimal due to the structure of the policy. First, only companies whose emissions intensities are higher than the benchmark will be required to surrender credits, thus incurring a credit-related cost that will affect their cost of production. Second, the cost of steel relative to the cost of the final product is often small; for instance, a 20 percent increase in the cost of steel per metric ton would only increase a vehicle's cost by 1 percent (ETC 2018).

A zero- or low-emissions steel mandate. A mandate that requires a certain percentage of zero- or low-emissions steel production would be a beneficial complement to a low-carbon product standard for steel. The existing zero-emissions vehicle mandate provides a template for a similar policy that could be applied to steel production. Such a policy would incentivize R\&D of emissions-free production technologies, which would, in turn, increase abatement options for the industry over time.

Funding for R\&D. To facilitate R\&D and reduce barriers to entry in the steel sector, R\&D funding should be provided in parallel with a low-carbon product standard. This would accelerate innovation and the development of new technologies, which are crucial to the success of decarbonization efforts in the steel industry. Funding must be carefully distributed, however, to ensure that funds reach projects that show promise for decarbonization.

Government procurement. A procurement program that relies on a voluntary reporting and certification standard could be implemented similar to voluntary programs for energy consumption, such as the EPA's Energy Star program. A voluntary emissions program could be similarly implemented for the steel industry. Such a program could rely on existing reporting protocols used under the
Greenhouse Gas Reporting Program and Energy Star program, which require emissions and production data from integrated mills and emissions data from minimills. Such a program, however, would require additional production data not currently reported by minimills.

The program could acknowledge low-carbon products with a certification according to the emissions intensity of the product, and this certification could be used to steer the government's procurement of steel products. This voluntary approach could result in emissions reductions and innovation across the industry, without involving many of the complexities associated with a mandatory product standard. Furthermore, such a program could set the stage for a product standard or for an economy-wide emissions trading program. Government procurement requirements could move the steel industry in the right direction; however, acting alone, they would not have considerable impact on the emissions intensity of steel production given that government procurement of steel amounts to approximately 3.3 percent of all steel consumption in the United States (Krupnick 2020).

Product value. Without careful design, a low-carbon product standard for steel could incentivize domestic production of low-value steel products with lower emissions intensities over high-value steel products. In the steel industry, emissions are greatly reduced by using scrap in the EAF production route, so producers might choose to shift production toward this production route as a way to lower their emissions intensity. This could mean a domestic shift toward lower-quality and lower-value products in the near term, until low emissions intensity production costs for high quality steel products reached parity with high emissions intensity production.

National defense. Steel is a trade-exposed industry, and as such, a drop in domestic production can readily be compensated for by an increase in foreign production. Steel is important for national defense, however, so such a shift in production, even if economically and environmentally advantageous, could have national security implications (BIS 2020). Although defense applications currently account for only about 3 percent of domestic steel consumption, maintaining a secure supply chain for domestic steel production is an important consideration when designing policies for reducing emissions in the steel industry. 


\section{CONCLUSIONS AND RECOMMENDATIONS}

The U.S. steel industry has many opportunities to reduce the emissions intensity of steel production through retrofits and shifts in production toward existing and new steelmaking technologies. These changes can be incentivized and accelerated by national policies that focus on reducing emissions in the steel sector. These policies, which include public procurement requirements, tax credits, research funding, and a low-carbon product standard, can act in harmony and result in substantial emissions reductions. A low-carbon product standard, in particular, can provide targeted incentives to reduce emissions across the entire range of steel products while inducing innovation and shifts in production.

This working paper offers recommendations for key design elements of a low-carbon product standard for steel that would result in a reduction in U.S. steelmaking emissions without impacting the international competitiveness of the industry. The recommended policy design elements for a low-carbon product standard for steel in the United States include the following:

A benchmark for each product category should include direct and indirect GHG emissions (Scope 1, Scope 2, and significant upstream Scope 3 emissions) and should be set to a percentage of the average emissions intensity for the domestic manufacturing of that product.

- The benchmark should be reduced over time according to abatement opportunities and emissions reduction goals for the industry.

Product categories should be set for each of the major finished steel products, including steel sheets, plates, bars, beams, pipes, and tubes.

Credits received for beating the benchmark are tradable, while credits must be surrendered for emissions exceeding the benchmark.

This paper also offers points of consideration and alternatives for these design elements, noting where more research is needed to analyze the impact of specific policy designs.

\section{ABBREVIATIONS}

$\begin{array}{ll}\text { Btu } & \text { British thermal unit } \\ \text { CCUS } & \text { carbon capture, use, and storage } \\ \mathrm{CO}_{2} \mathrm{e} & \text { carbon dioxide equivalent } \\ \mathrm{DRI} & \text { direct-reduced iron } \\ \text { EAF } & \text { electric arc furnace } \\ \text { EGU } & \text { electricity generating unit } \\ \text { EPD } & \text { environmental product declaration } \\ \text { ETS } & \text { emissions trading scheme } \\ \text { GHG } & \text { greenhouse gas } \\ \text { IPPU } & \text { industrial process and product use } \\ \text { kWh } & \text { kilowatt-hour } \\ \text { LCFS } & \text { Low-Carbon Fuel Standard } \\ \text { MMBtu } & \text { million British thermal units } \\ \text { Mt } & \text { million metric tons } \\ \text { OBPS } & \text { Output-Based Pricing System } \\ \text { R\&D } & \text { research and development }\end{array}$


1. Electricity is assumed to have an emissions intensity of $131 \mathrm{kgCO}_{2} \mathrm{e} /$ MMBtu.

2. For more information, see the Greenhouse Gas Protocol website, https://ghgprotocol.org/.

3. See, for example, the discussion regarding electric generating units (EGUs) in Nordhaus and Gutherz (2014). There are significant differences between the use of section 111(d) for steel facilities as compared with EGUs, but this provides an overview of a number of the primary potential legal hurdles.
AISI (American Iron and Steel Institute). 2019. American Iron and Steel Institute: Profile 2019. Washington, DC: American Iron and Steel Institute.

Allianz Research. 2020. European Climate Policy Goes Global. Munich: Allianz Research. https://www.allianz.com/content/dam/onemarketing/ azcom/Allianz_com/economic-research/publications/specials/en/2020/ october/2020_10_14_CarbonBorderTax.pdf.

ArcelorMittal. 2019. "News: Siderwin, Targeting Radically New Steel Production without $\mathrm{CO}_{2}$ Emissions." https://automotive.arcelormittal.com/ news_and_stories/news/2019Siderwin.

Baker, S., J. Stolaroff, G. Peridas, S. Pang, H. Goldstein, F. Lucci, W. Li, et al. 2020. Getting to Neutral: Options for Negative Carbon Emissions in California. Livermore, CA: Lawrence Livermore National Laboratory. https://www-gs.IInl. gov/content/assets/docs/energy/Getting_to_Neutral.pdf.

Balserak, P. 2020. Personal communication between John Feldmann, Research Analyst, World Resources Institute, and Paul Balserak, Vice President for Environment, American Iron and Steel Institute, October 22.

BEA (Bureau Economic Analysis). 2018. "Total Requirements Table." Updated April 9. https://www.bea.gov/help/glossary/total-requirements-table.

Birat, J.-P., M. Antoine, A. Dubs, H. Gaye, Y. Lassat, R. Nicolle, and J.L. Roth. 1993. "Towards a Carbon-Free Steel Production Route?" La Revue de Metallurgie 90 (3): 411-22. https://doi.org/10.1051/metal/199390030411.

BIS (Bureau of Industry and Security). 2020. "Publication of a Report on the Effect of Imports of Steel on the National Security: An Investigation Conducted under Section 232 of the Trade Expansion Act of 1962, as Amended." Federal Register, July 6. https://www.federalregister.gov/ documents/2020/07/06/2020-14359/publication-of-a-report-on-the-effectof-imports-of-steel-on-the-national-security-an-investigation.

Boyd, G., M. Doolin, and S. Zhang. 2016. Development of Energy Star Energy Performance Indicator for Integrated Steel Mills. Washington, DC: U.S. Environmental Protection Agency, https://www.energystar.gov/sites/default/ files/tools/Integrated\%20Steel\%20EPI\%20Documentation_08152016_508. pdf.

California State Legislature. 2017, "Article 5. Buy Clean California Act [3500-3505]." California Legislative Information. https://leginfo.legislature. ca.gov/faces/codes_displayText.xhtml?division=2.\&chapter=3.\&part=1.\&law Code $=$ PCC\&article $=5$.

Conejo, A.N., J.-P. Birat, and A. Dutta. 2020. "A Review of the Current Environmental Challenges of the Steel Industry and Its Value Chain." Journal of Environmental Management 259 (April): 1-9. https://doi.org/10.1016/j. jenvman.2019.109782.

DOE (U.S. Department of Energy). 2015. "Bandwidth Study on Energy Use and Potential Energy Saving Opportunities in U.S. Iron and Steel Manufacturing." Washington, DC: DOE. https://www.energy.gov/sites/prod/files/2015/08/f26/ iron_and_steel_bandwidth_report_0.pdf.

EIA (U.S. Energy Information Administration). 2020. Annual Energy Outlook 2020. Washington, DC: ElA. https://www.eia.gov/outlooks/aeo/pdf/ AE02020\%20Full\%20Report.pdf. 
EPA (U.S. Environmental Protection Agency). 2009. Technical Support Document for the Iron and Steel Sector: Proposed Rule for Mandatory Reporting of Greenhouse Gases. Washington, DC: EPA. https://www.epa.gov/ sites/production/files/2015-02/documents/tsd_iron_and_steel_epa_9-808.pdf.

EPA. 2020a. "Emission Factors for Greenhouse Gas Inventories." Washington, DC: EPA. https://www.epa.gov/sites/production/files/2020-04/documents/ ghg-emission-factors-hub.pdf.

EPA. 2020b. U.S. Greenhouse Gas Emissions and Sinks: 1990-2018. Washington, DC: EPA. https://www.epa.gov/sites/production/files/2020-04/ documents/us-ghg-inventory-2020-main-text.pdf.

EPA. 2021. "Greenhouse Gas Reporting Program (GHGRP)." https://www.epa. gov/ghgreporting.

ETC (Energy Transitions Commission). 2018. Mission Possible: Reaching NetZero Carbon Emissions from Harder-to-Abate Sectors by Mid-century. London: ETC. https://www.energy-transitions.org/wp-content/uploads/2020/08/ ETC_MissionPossible_FullReport.pdf.

Global CCS Institute. n.d. "Facilities Database." https://co2re.co/FacilityData. Accessed February 23, 2021.

Government of Canada. 2020. "Output-Based Pricing System Regulations (SOR/2019-266)." Justice Laws Website. https://laws-lois.justice.gc.ca/eng/ regulations/SOR-2019-266/section-sched1185035.html?txthl=steel.

IEA (International Energy Agency). 2020. Iron and Steel Technology Roadmap: Towards More Sustainable Stee/making. Paris: IEA. https://www.iea.org/ reports/iron-and-steel-technology-roadmap.

ITA (International Trade Administration), 2020. Steel Imports Report: United States. Global Steel Trade Monitor. Washington, DC: ITA. https://legacy,trade. gov/steel/countries/pdfs/imports-us.pdf.

Keith, D.W., G. Holmes, D. St. Angelo, and K. Heidel. 2018. "A Process for Capturing C0 from the Atmosphere." Joule 2 (8): 1573-94. https://doi. org/10.1016/j.joule.2018.05.006.

King, B., J. Larsen, W. Herndon, and T. Houser. 2020. Clean Products Standard: A New Approach to Industrial Decarbonization. New York: Rhodium Group, https://rhg.com/research/clean-products-standard-industrialdecarbonization/.

Krupnick, A. 2020. Green Public Procurement for Natural Gas, Cement, and Steel. Resources for the Future. Washington, DC: Resources for the Future. https://media.rff.org/documents/RFF_WP_20-17_Green_Public_ Procurement_for_Natural_Gas_Cement_and_Steel.pdf.

Norhaus, R.R., and I.W. Gutherz. 2014. "Regulation of $\mathrm{CO}_{2}$ Emissions from Existing Power Plants under $\$ 111(\mathrm{~d})$ of the Clean Air Act: Program Design and Statutory Authority." Environmental Law Reporter 44 (5): 10366. https://www. vnf.com/files/9035_44\%2010366.pdf.

Pardo, N., J.A. Moya, and K. Vatopoulos. 2012. Prospective Scenarios on Energy Efficiency and $\mathrm{CO}_{2}$ Emissions in the EU Iron \& Steel Industry. Luxembourg: European Union. https://publications.jrc.ec.europa.eu/repository/bitstream/ JRC74811/ld1a25543enn.pdf.
SSAB. n.d. "First in Fossil-Free Steel. Using HYBRIT Technology." https://www. ssab.com/company/sustainability/sustainable-operations/hybrit. Accessed February 23, 2021.

USGS (U.S. Geological Survey). 2020. "Iron and Steel." In Mineral Commodity Summaries 2020, 82-83. Reston, VA: USGS. https://pubs.usgs.gov/ periodicals/mcs2020/mcs2020-iron-steel.pdf.

USGS. n.d. "Iron Ore Statistics and Information." National Minerals Information Center. https://www.usgs.gov/centers/nmic/iron-ore-statisticsand-information. Accessed February 23, 2021.

worldsteel (World Steel Association), 2019. Fact sheet: Steel and raw materials. Brussels: World Steel Association. https://www.worldsteel. org/en/dam/jcr:16ad9bcd-dbf5-449f-b42c-b220952767bf/fact_ raw\%2520materials_2019.pdf

worldsteel. 2020. 2020 World Steel in Figures. Brussels: World Steel Association. https://www.worldsteel.org/en/dam/jcr:f7982217-cfde-4fdc8ba0-795ed807f513/World\%2520Steel\%2520in\%2520Figures\%25202020i. pdf.

Worrell, E., N. Martin, and L. Price. 1999. Energy Efficiency and Carbon Dioxide Emissions Reduction Opportunities in the U.S. Iron and Steel Sector. Berkeley, CA: Ernest Orlando Lawrence Berkeley National Laboratory. https://www. osti.gov/servlets/purl/760282. 


\section{ACKNOWLEDGMENTS}

The authors are grateful to numerous individuals who provided valuable input, feedback, and support to this work. We thank our external reviewers for sharing their expertise and insights: Paul Balserak, Vincent Chevrier, Jed Ela, Mike Fowler, Jean-Theo Ghenda, Meghan Lewis, Hélène Pilorgé, Michael Sortwell, Rebecca Stevens, and Mark Thimons.

Thanks also goes to WRI colleagues for their thoughtful review, comments, insights, and guidance: Nate Aden, Tyler Clevenger, Devashree Saha, Rajat Shrestha, Jen Wilcox, and Gillian Zwicker. We would especially like to thank Dan Lashof for his guidance.

Although the contributions from reviewers are greatly appreciated, the views presented in this paper reflect those of the authors alone.

We also wish to thank Romain Warnault, Emily Matthews, Lauri Scherer, Emilia Suarez, Carni Klirs for editing, design, and production and Matt Herbert for communications support.

This project was made possible through the generous funding of Gates Ventures and Breakthrough Energy.

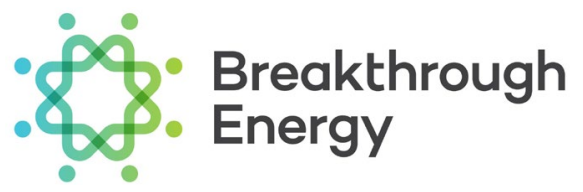

\section{ABOUT THE AUTHORS}

John Feldmann is a Research Analyst in the U.S. Climate Initiative at WRI focusing on sustainable fuels and decarbonizing industrial processes.

Contact: john.feldmann@wri.org

Kevin Kennedy is a Senior Fellow in the U.S. Climate Initiative at WRI, where he leads work on market-based climate policies and on subnational climate action.

Contact: kevin.kennedy@wri.org
World Resources Institute is a global research organization that turns big ideas into action at the nexus of environment, economic opportunity, and human well-being.

\section{Our Challenge}

Natural resources are at the foundation of economic opportunity and human well-being. But today, we are depleting Earth's resources at rates that are not sustainable, endangering economies and people's lives. People depend on clean water, fertile land, healthy forests, and a stable climate. Livable cities and clean energy are essential for a sustainable planet. We must address these urgent, global challenges this decade.

\section{Our Vision}

We envision an equitable and prosperous planet driven by the wise management of natural resources. We aspire to create a world where the actions of government, business, and communities combine to eliminate poverty and sustain the natural environment for all people.

\section{Our Approach}

COUNT IT

We start with data. We conduct independent research and draw on the latest technology to develop new insights and recommendations, Our rigorous analysis identifies risks, unveils opportunities, and informs smart strategies. We focus our efforts on influential and emerging economies where the future of sustainability will be determined.

\section{CHANGE IT}

We use our research to influence government policies, business strategies, and civil society action. We test projects with communities, companies, and government agencies to build a strong evidence base. Then, we work with partners to deliver change on the ground that alleviates poverty and strengthens society. We hold ourselves accountable to ensure our outcomes will be bold and enduring.

SCALE IT

We don't think small. Once tested, we work with partners to adopt and expand our efforts regionally and globally. We engage with decision-makers to carry out our ideas and elevate our impact. We measure success through government and business actions that improve people's lives and sustain a healthy environment.

cc) creative Copyright 2021 World Resources Institute. This work is licensed under the Creative Commons Attribution 4.0 International License.

commons (i) To view a copy of the license, visit http://creativecommons.org/licenses/by/4.0/ 